Intravitreal anti-VEGF therapy is not associated with a higher risk of all-cause mortality in patients with macular oedema caused by posterior segment vascular diseases

\title{
Loukovaara, Sirpa
}

2021-09

Loukovaara , S \& Haukka , J 2021, ' Intravitreal anti-VEGF therapy is not associated with a higher risk of all-cause mortality in patients with macular oedema caused by posterior segment vascular diseases ' , Acta Ophthalmologica , vol. 99 , no. 6 , pp. E893-E898 . https://doi.org/10.1111/aos.14

http://hdl.handle.net/10138/338713

https://doi.org/10.1111/aos.14717

acceptedVersion

Downloaded from Helda, University of Helsinki institutional repository.

This is an electronic reprint of the original article.

This reprint may differ from the original in pagination and typographic detail.

Please cite the original version. 
Intravitreal anti-VEGF therapy is not associated with a higher risk of all-cause mortality in patients with macular edema caused by posterior segment vascular diseases

Sirpa Loukovaara ${ }^{1} \&$ Jari Haukka ${ }^{2,3}$

${ }^{1}$ Unit of Vitreoretinal Surgery, Department of Ophthalmology, Helsinki University Hospital, and Individualized Drug Therapy Research Program, University of Helsinki, Helsinki, Finland

${ }^{2}$ Department of Public Health, University of Helsinki, Helsinki, Finland

${ }^{3}$ Faculty of Medicine and Health Technology, Tampere University, Finland

Conflict of interest: no potential conflict of interest relevant to this report.

Sources of Funding: This study was supported by Y1014SI004 grant (SL), and funded by University of Helsinki, Finland (JH).

Correspondence to Sirpa Loukovaara, MD, PhD, Unit of Vitreoretinal Surgery, Department of Ophthalmology, University of Helsinki and Helsinki University Hospital, Haartmaninkatu 4 C, 00290 Helsinki, Finland, Europe. Tel. 358-50-4271566. E-mail: sirpa.loukovaara@ hus.fi

Keywords: all-cause mortality, anti-VEGF, diabetic macular oedema, retinal vein occlusion, wet age-related macular degeneration 


\begin{abstract}
Purpose: To examine whether real world clinical patients with macular odema (MO) receiving intravitreal anti-vascular endothelial growth factor (VEGF) therapy have a higher mortality compared with a matched reference population.

Methods: A population-based, retrospective cohort study of 26386 patients from Finland, from January 1, 2001, to December 31, 2017.

Index patients were identified through the Caring Epidemiology Project database, receiving at least one intravitreal anti-VEGF injection for wet age-related macular degeneration (AMD, $\mathrm{n}=2243,48.61 \%)$, diabetic $\mathrm{MO}(\mathrm{n}=744,16.12 \%)$, MO due to retinal vascular occlusion $(\mathrm{n}=589$, $12.77 \%)$, or other MO $(\mathrm{n}=1038,22.5 \%)$. For each individual treated with intravitreal injection $(\mathrm{n}=4614)$, five age- , sex- , calendar year-, and hospital district- matched control individuals $(n=21772)$ were chosen. Baseline data of chronic conditions were available. All-cause and cause-specific mortality was analyzed using Cox's proportional hazards model.
\end{abstract}

Results: In general, the anti-VEGF treated patients had a higher prevalence of systemic conditions, including diabetes (60.1\% vs. $46.8 \%$, p<0.001), chronic hypertension (38.4\% vs. $34.6 \%, \mathrm{p}<0.001)$, in hospital-treated ischemic heart disease $(23.1 \%$ vs. $21.5 \%, \mathrm{p}=0.014)$, and glaucoma $(11.1 \%$ vs. $6.3 \%, \mathrm{p}<0.001)$ than controls. There was no difference in all-cause mortality between the anti-VEGF treated patients and matched controls $(p=0.62)$

In unadjusted Kaplan Meier analysis of wet AMD subgroup, all-cause mortality was lower in anti-VEGF treated patients than matched controls $(\mathrm{p}=0.015)$, but adjusted Cox's proportional hazards model showed no difference in the risk of all-cause mortality (HR 0.85, 95\% CI 0.661.09).

Conclusions: Intravitreal anti-VEGF therapy was not associated with an increase in the risk of mortality in patients with MO compared with age- and sex-matched controls. 


\section{Introduction}

Inflammation and retinal or choroidal vascular leakage-related posterior segment eye diseases such as diabetic macular oedema (DMO), macular oedema due to retinal vein occlusion (MORVO), and wet age-related macular degeneration (AMD) are potentially sight-threatening ocular manifestations of systemic diseases. Association between AMD and cardiovascular diseases, hypertension, cerebrovascular disease, dyslipidaemia, chronic kidney disease and neurodegenerative disorders has clearly been reported earlier (Tan et al. 2007; Cheung and Wong 2014).

Despite differences in the pathogenesis, the prognosis of all of these vascular eye conditions with MO has improved remarkably, since the invent of intravitreal anti vascular endothelial growth factor (anti-VEGF) therapy in 2005. Indeed, multiple anti-VEGF injections have become the first line treatment in all of them. Today, the ophthalmic adverse events related to anti-VEGF injections have been studied vastly, and no overall safety concerns between the antiangiogenic drugs to treat DMO, MO-RVO or wet AMD have been found (Virgili et al. 2017; Nguyen et al. 2018; Maloney et al. 2020). In addition, there is evidence that systemic adverse events (SAEs) including all-cause mortality, and arteriothrombotic events, are very unlikely in anti-VEGF treated patients (Scott et al. 2015; Baillif et al. 2018; Maloney et al. 2020). However, due to the paucity of studies today, there are still some concerns related to long-term SAEs and intravitreally injected anti-VEGF compounds (Virgili e al. 2017; Nguyen et al. 2018; Costagliola et al. 2019).

Thus, we aimed to examine whether real-world clinical cohort of patients with MO treated with intravitreal anti-VEGF therapy have a higher mortality compared with age-, sex- and hospital district-matched reference population. Special interest was paid in the anti-VEGF treated wet AMD eyes, since this condition is globally the most commonly anti-VEGF treated one.

\section{Study design and Methods}

The population cohort was constructed based on the nationwide CARING Project in Finland (Fig. 1), where we studied the incidence of cancer in Finnish population during 21 years of follow-up (Niskanen et al. 2020).

Briefly, in this continuation study, the population consisted of two groups: ophthalmic patients who had received intravitreal injection (anti-VEGF; procedure code CKD05) and matched reference population without.

Our study population consisted of 26386 individuals, comprising 4614 index cases including 1.) wet age-related macular degeneration (AMD, $n=2243,48.61 \%$ ), 2.) diabetic macular oedema (DMO, $\mathrm{n}=744,16.12 \%), 3$.) macular oedema due to retinal vascular occlusion (MO-RVO, $\mathrm{n}=589,12.77 \%)$, or 4 .) other $\mathrm{MO}(\mathrm{n}=1038,22.5 \%)$, and 21772 matched reference subjects. 
We aimed to match the five reference individuals for each index case treated with intravitreal injection by sex, age ( \pm 1 year), region (hospital district) and start of the follow-up date (calendar year). For 4034 cases we found five reference individuals, for 172 cases four, for 197 cases three, for 112 cases two, and for 99 cases one matched reference individual.

This research adheres to the Declaration of Helsinki. The study plan was approved by the Faculty of Medicine, University of Helsinki, the ethic committee on January 17, 2012 (Ref 02/2012).

We obtained the prescription data from the Social Insurance Institution (permission Kela 16/522/2012).

Cancer data was obtained from the Finnish Cancer Registry, and it included the diagnosis (ICDO-3 code) and date of diagnosis (THL/264/5.05.00/2012).

Follow-up started on the occurrence of the first intravitreal anti-VEGF injection procedure and ended on December 31, 2017 or on the date of death, whichever occurred first (Nordic MedicoStatistical Committee 2010).

We obtained the information of death (the date and cause of death) and socio-economic status from Statistics Finland (permission TK-53-214-12).

We used mortality data, i.e. death from any cause, from coronary heart disease (ICD-10 codes I20-I25), or stroke (ICD-10 codes I60-I69) as the end-point events. The main aim was to clarify whether there is a difference in all-cause or cause-specific mortality between the study groups.

\section{Statistical analysis}

We calculated log-rank tests and Kaplan-Meier curves for both end-points and all variables. We performed time to event analyses using Cox's proportional hazards models. We included the following variables in Cox's proportional hazards models: indicator for intravitreal injection (no/yes), IHD even in one year before start of follow-up (no/yes), diabetes (no/yes), Parkinson's disease (no/yes), severe psychotic and other severe mental disorder (no/yes), glaucoma (no/yes), chronic cardiac insufficiency (no/yes), chronic hypertension (no/yes), chronic coronary heart disease (no/yes), chronic arrhythmias (no/yes), ulcerative colitis and Crohn's disease (no/yes).

Matching was taken into account by using matching set as strata and risk factors as predictors. We report the hazard ratio (HR) and the $95 \%$ confidence interval (CI).

All analysis was performed using R language (R Core Team 2019).

We checked proportionality with a test based on weighted residuals (Grambsch \& Therneau 1994), and found no evidence for non-proportionality.

\section{Results}

Demographics and comorbid conditions of our study population are given in Table 1 . There were differences in socio-economic status between the matched controls and anti-VEGF treated study patients (Table 1). Majority of patients $(n=13$ 669) were female with the mean age of $65.8(11.4)$ 
years. Compared to the matched reference group, there were more cases with diabetes, hypertension, and glaucoma in the anti-VEGF treated group (in all $\mathrm{p}<0.001$ ). In addition, in hospital-treated ischemic heart disease was more common in the index group $(\mathrm{p}=0.014)$. However, severe mental disorders occurred less commonly in anti-VEGF treated patients compared to matched reference cases $(\mathrm{P}=0.004)$.

Out of 4614 persons, $48.61 \%$ received anti-VEGF treatment due to wet AMD, $16.12 \%$ due to DMO, $12.77 \%$ due to DO-RVO, and $22.5 \%$ due to the other MO condition.

The mean follow-up after intravitreal injection was 3.96 years. There was a higher mortality in patients with diabetes, cancer, Parkinson's disease, severe mental disorders, chronic cardiac insufficiency, heart disease, and hypertension, and glaucoma (Table 2). In addition, the all-cause mortality varied according to the socio-economic status. Of note, log-rank test did not show difference in all-cause mortality between the anti-VEGF treated patients and matched controls $(\mathrm{p}=0.62)$, mortality rate ratio being 1.04 (95\% CI 0.97 - 1.12) (Table 2).

Adjusted Cox's proportional hazards model showed no difference in the risk of all-cause mortality between anti-VEGF treated and non-treated reference group (HR 0.966, CI 0.879 1.061). Hospital-treated ischemic heart disease or cerebrovascular disease (stroke) did not modify the effect (HR for interaction 1.096, CI 0.920-1.305).

\section{Sub-analysis of wet AMD patients}

The results of the subgroup analysis showed that the patients in wet AMD group $(n=2243)$ had more often chronic cardiovascular disease $(\mathrm{p}=0.005)$, hypertension $(\mathrm{p}=0.045)$, and glaucoma $(\mathrm{p}=0.004)$ than the matched controls.

Noteworthy, the cerebrovascular disease (stroke) previously treated in a hospital setting was more common in matched controls than anti-VEGF treated patients $(\mathrm{p}=0.045)$. When only patients with wet AMD were analyzed, the mortality in these patients treated in different hospital districts $(\mathrm{n}=22)$ did not differ (log-rank test $\mathrm{p}=0.25)$.

The unadjusted Kaplan-Meier analysis did show slight difference in all-cause mortality between the anti-VEGF treated AMD patients and matched controls ( $\mathrm{p}=0.015$ ) (Fig 2). Of note, adjusted Cox proportional hazards model showed no difference in all-cause mortality between anti-VEGF treated wet AMD patients and matched controls (HR 0.85, 0.66 - 1.09). Neither did hospitaltreated ischemic heart disease modify the effect (HR 0.844, 0.669 -1.064). 


\section{Discussion}

In this retrospective population-based cohort study performed in Finland, we demonstrated that the intravitreal anti-VEGF therapy is not associated with a higher risk of all-cause mortality in patients with MO due to wet AMD, diabetes, or RVO after adjustment for age, gender, calendaryear and hospital district. Of note, our study is in line with the very recent findings of a large study, showing that intravitreal anti-VEGF pharmacotherapy is well-tolerated and can be prescribed safely for most common posterior segment pathologies including wet AMD, DMO and MO related to RVO (Maloney et al. 2020).

Since 2005, the use of anti-VEGF drugs has replaced laser photocoagulation as the standard of care, and globally changed the treatment praxis of wet AMD, DMO and MO due to RVO (Rosenfeld et al. 2006; Campa et al. 2016; Virgili et al. 2017). Globally, and in Finland, ophthalmic patients with MO have been treated with unlicensed intravitreal bevacizumab (Avastin, Genentech, CA, USA), with licensed ranibizumab (Lucentis, Genentech, CA, USA) 2006 onwards (for wet AMD, 2010 for RVO, and 2012 for DMO), or with licensed aflibercept (Eylea, Regeneron, Tarrytown, NY) 2011 onwards, first for wet AMD, then for MO with RVO since 2012, and finally, for DMO since 2014.

Our study showed that systemic conditions such as diabetes, chronic hypertension, chronic heart disease, as well as glaucoma were more common in anti-VEGF treated patients in general as compared to age- and gender matched controls. Noteworthy, in the biggest group, i.e. among the anti-VEGF treated wet AMD cases, chronic hypertension, chronic heart disease, and glaucoma remained more prevalent as compared to matched controls, confirming previous findings (Tan et al. 2007; Cheung and Wong 2014).

Previously, fifteen randomized clinical trials of good methodological quality including 8320 wet AMD patients have demonstrated the beneficial effect of anti-VEGF therapy on visual and anatomical outcomes (Nguyen et al. 2018). In addition, anti-VEGF drugs effectively improve vision in people with DMO and RVO (Campa et al. 2016; Virgili et al. 2017). In our study, there were 2243 patients with wet AMD compared to 3252 patients with wet AMD in MARINA, ANCHOR, SAILOR, and PIER studies. However, we need to acknowledge that our retrospective study was limited to the three types of anti-VEGF agents used and ophthalmic outcomes. Our data did not contain information about used intravitreal anti-VEGF drug making comparison between different anti-VEGF substances impossible. The strength of our register-based study is a large population-based sample and long follow-up with longitudinal health information. It should be taken into account that a possibility remains that the selection of patients who were treated with anti-VEGF injections may have biased the results. In epidemiological studies, there are most likely some confounders that cannot be fully adjusted.

We carried out sensitivity analyses for unmeasured confounding variables using E-value (Vander Weele \& Ding 2017). It turned out that E-value for association was 0.64, corresponding hazard ratio (HR) 0.85 of anti-VEGF treated AMD patients. This means that the observed HR of 0.85 for anti-VEGF treatment could be explained away by an unmeasured confounder that was 
associated with both the treatment and the outcome by a risk ratio of 0.64 -fold each, above and beyond the measured confounders, but weaker confounding could not do so.

To conclude, the pathogenesis of MO associated with diabetes, RVO, and wet AMD, is multifactorial, involving a complex interaction of metabolic, functional, genetic and environmental factors. Intravitreal anti-VEGF agents used to treat MO can penetrate into blood circulation, and influence systemic vascular health, especially in vulnerable patients (Avery et al. 2014). However, according to our epidemiological results, anti-VEGF treatment may be used to improve visual prognosis in the patients with posterior segment pathologies such as wet AMD, $\mathrm{DMO}$, and MO related to RVO without an increased risk of all-cause mortality. On the contrary, worth to mention is that the anti-VEGF treated patients had a higher prevalence of systemic conditions, including diabetes, chronic hypertension, in hospital-treated ischemic heart disease, as well as glaucoma than the matched controls. More excitingly, according to unadjusted Kaplan Meier analysis, the risk of all-cause mortality in the anti-VEGF treated wet AMD patients seemed to be lower than in the matched controls. Our findings are potentially interesting, but should be studied further in different populations with various treatment indications. 


\section{References}

Avery RL, Castellarin AA, Steinle NC, et al. (2014): Systemic pharmacokinetics following intravitreal injections of ranibizumab, bevacizumab or aflibercept in patients with neovascular AMD. British Journal of Ophthalmology 98:1636-1641.

Baillif S, Levy B, Girmens JF, Dumas S, Tadayoni R (2018):Tolérance systémique des injections intravitréennes d'anti-VEGF [Systemic safety following intravitreal injections of anti-VEGF]. J Fr Ophtalmol. 41(3):271-276. doi:10.1016/j.jfo.2017.11.006

Campa C, Alivernini G, Bolletta E, Parodi MB, Perri P (2016): Anti-VEGF Therapy for Retinal Vein Occlusions. Curr Drug Targets. 2016;17(3):328-336. doi:10.2174/1573399811666150615151324

Cheung CM, Wong TY (2014): Is age-related macular degeneration a manifestation of systemic disease? New prospects for early intervention and treatment. J Intern Med. 2014;276(2):140-153. doi:10.1111/joim. 12227

Costagliola C, Morescalchi F, Duse S, et al. (2019): Systemic thromboembolic adverse events in patients treated with intravitreal anti-VEGF drugs for neovascular age-related macular degeneration: an update. Expert Opin Drug Saf. 18(9):803-815.

doi: $10.1080 / 14740338.2019 .1643838$

Dalvin LA, Starr MR, AbouChehade JE, et al. (2019): Association of Intravitreal Anti-Vascular Endothelial Growth Factor Therapy With Risk of Stroke, Myocardial Infarction, and Death in Patients With Exudative Age-Related Macular Degeneration. JAMA Ophthalmol. 137(5):483490. doi:10.1001/jamaophthalmol.2018.6891

Grambsch, P.M. and Therneau, T.M. (1994) Proportional Hazards Tests and Diagnostics Based on Weighted Residuals. Biometrika, 81, 515-526. https://doi.org/10.1093/biomet/81.3.515

Maloney MH, Payne SR, Herrin J, Sangaralingham LR, Shah ND, Barkmeier AJ. Risk of Systemic Adverse Events after Intravitreal Bevacizumab, Ranibizumab, and Aflibercept in Routine Clinical Practice. Ophthalmology. 2020 Aug 8:S0161-6420(20)30782-X. doi: 10.1016/j.ophtha.2020.07.062. Epub ahead of print. PMID: 32781110.

Nguyen CL, Oh LJ, Wong E, Wei J, Chilov M (2018): Anti-vascular endothelial growth factor for neovascular age-related macular degeneration: a meta-analysis of randomized controlled trials. BMC Ophthalmol. 2018;18(1):130. Published 2018 May 30. doi:10.1186/s12886-0180785-3

Niskanen L, Partonen T, Auvinen A, Haukka J (2020): Trends and predictors in all-cause and cause-specific mortality in diabetic and reference populations during 21 years of follow-up. J Epidemiol Community Health Published Online First: 03 July 2020. doi: 10.1136/jech-2019213602

Nordisk Medicinal-Statistisk Komité (2010): NOMESCO classification of surgical procedures. Copenhagen: Nordic Medico-Statistical Committee. 
Rosenfeld PJ, Brown DM, Heier JS, et al. (2006): Ranibizumab for neovascular age-related macular degeneration. N Engl J Med. 355(14):1419-1431. doi:10.1056/NEJMoa054481

Scott LJ, Chakravarthy U, Reeves BC, Rogers CA (2015): Systemic safety of anti-VEGF drugs: a commentary. Expert Opin Drug Saf. 14(3):379-388. doi:10.1517/14740338.2015.991712

Tan JS, Mitchell P, Smith W, Wang JJ (2007): Cardiovascular risk factors and the long-term incidence of age-related macular degeneration: the Blue Mountains Eye Study. Ophthalmology. 114(6):1143-1150. doi:10.1016/j.ophtha.2006.09.033

Vander Weele TJ, Ding P (2017): Sensitivity Analysis in Observational Research: Introducing the E-Value. Annals of Internal Medicine 167: 268.

Virgili G, Parravano M, Evans JR, Gordon I, Lucenteforte E (2017): Anti-vascular endothelial growth factor for diabetic macular oedema: a network meta-analysis. Cochrane Database Syst Rev. 2017;6(6):CD007419. Published 2017 Jun 22. doi:10.1002/14651858.CD007419.pub5 
Figure 1. Flowchart of study population construction.

Figure 2. The unadjusted Kaplan-Meier curve and log-rank test for all-cause mortality for wet AMD population $(\mathrm{N}=2243)$ with intravitreal anti-VEGF injection (dashes) and matched reference (continuous line). 
Table 1. Basic characteristics of study population.

\begin{tabular}{|c|c|c|c|c|}
\hline & Reference & $\begin{array}{l}\text { Intravitreal } \\
\text { anti-VEGF } \\
\text { Injection }\end{array}$ & $\mathbf{p}$ & All \\
\hline $\mathrm{N}$ & 21772 & 4614 & & 26386 \\
\hline \multicolumn{5}{|l|}{ Demographic factors } \\
\hline Age, mean years (SD) & $65.73(11.3)$ & $65.89(11.8)$ & 0.376 & $65.76(11.4)$ \\
\hline Female, n (\%) & $\begin{array}{l}11272 \\
(51.8)\end{array}$ & $2397(52.0)$ & 0.839 & $13669(51.8)$ \\
\hline \multicolumn{5}{|l|}{ Systematic diseases in baseline } \\
\hline Diabetes, n (\%) & $\begin{array}{l}10200 \\
(46.8)\end{array}$ & $2775(60.1)$ & $<0.001$ & $12975(49.2)$ \\
\hline Cancer, n (\%) & $693(3.2)$ & $158(3.4)$ & 0.425 & $851(3.2)$ \\
\hline Thyroid insufficiency, $\mathrm{n}(\%)^{*}$ & $912(4.2)$ & $189(4.1)$ & 0.806 & $1101(4.2)$ \\
\hline Parkinson's disease, $n(\%)^{*}$ & $238(1.1)$ & $46(1.0)$ & 0.619 & $284(1.1)$ \\
\hline Severe mental disorders, $\mathrm{n}(\%)^{*}$ & 748 ( 3.4) & $120(2.6)$ & 0.004 & $868(3.3)$ \\
\hline Chronic cardiac insufficiency, $\mathrm{n}(\%)^{*}$ & $736(3.4)$ & $185(4.0)$ & 0.038 & $921(3.5)$ \\
\hline Chronic hypertension, $\mathrm{n}(\%)^{*}$ & 7534 (34.6) & $1770(38.4)$ & $<0.001$ & $9304(35.3)$ \\
\hline Chronic coronary heart disease, $\mathrm{n}(\%)^{*}$ & $3400(15.6)$ & $762(16.5)$ & 0.134 & $4162(15.8)$ \\
\hline Chronic arrhythmias, n (\%)* & $924(4.2)$ & $214(4.6)$ & 0.247 & $1138(4.3)$ \\
\hline Ulcerative colitis and Crohn's disease, n (\%)* & $182(0.8)$ & $37(0.8)$ & 0.887 & $219(0.8)$ \\
\hline \multicolumn{5}{|l|}{ Ophthalmic parameters } \\
\hline Glaucoma, n (\%)* & $1378(6.3)$ & $511(11.1)$ & $<0.001$ & $1889(7.2)$ \\
\hline \multicolumn{5}{|l|}{ Cardiovascular events before start of follow-up } \\
\hline IHD ever before, $\mathrm{n}(\%)^{* *}$ & $4674(21.5)$ & $1067(23.1)$ & 0.014 & $5741(21.8)$ \\
\hline IHD in half year before, $\mathrm{n}(\%)^{* *}$ & $704(3.2)$ & $201(4.4)$ & $<0.001$ & 905 ( 3.4) \\
\hline IHD in year before, $\mathrm{n}(\%)^{* *}$ & 1191 ( 5.5) & $317(6.9)$ & $<0.001$ & $1508(5.7)$ \\
\hline Stroke ever before, $\mathrm{n}(\%)^{* *}$ & 2155 ( 9.9) & $466(10.1)$ & 0.697 & $2621(9.9)$ \\
\hline Stroke in half year before, $\mathrm{n}(\%)^{* *}$ & $309(1.4)$ & $69(1.5)$ & 0.743 & $378(1.4)$ \\
\hline Stroke in year before, $\mathrm{n}(\%)^{* *}$ & $511(2.3)$ & $118(2.6)$ & 0.425 & $629(2.4)$ \\
\hline Socio-economic status & & & 0.001 & \\
\hline Upper-level employees & $1170(5.4)$ & $191(4.1)$ & & $1361(5.2)$ \\
\hline Self-employed & $993(4.6)$ & $221(4.8)$ & & $1214(4.6)$ \\
\hline Lower-level employees & $1744(8.0)$ & $327(7.1)$ & & $2071(7.8)$ \\
\hline Manual workers & $2230(10.2)$ & $460(10.0)$ & & $2690(10.2)$ \\
\hline Students & $96(0.4)$ & $21(0.5)$ & & $117(0.4)$ \\
\hline
\end{tabular}




\begin{tabular}{|r|r|r|r|r|}
\hline Pensioners & $\begin{array}{r}14136 \\
(64.9)\end{array}$ & $3048(66.1)$ & $17184(65.1)$ \\
\hline Others & $1403(6.4)$ & $346(7.5)$ & & $1749(6.6)$ \\
\hline
\end{tabular}

IHD, ischemic heart disease. P testing difference between the reference population and cases.

*based on special reimbursement right; ${ }^{* *}$ based on hospitalization 
Table 2. All-cause mortality and mortality risk ratios during follow-up with $95 \%$ confidence intervals. Mortality risk ratios based on univariate models.

\begin{tabular}{|c|c|c|c|c|c|}
\hline & & $\begin{array}{l}\text { Person-years } \\
(1000)\end{array}$ & $\begin{array}{l}\text { Number of } \\
\text { deaths }\end{array}$ & $\begin{array}{l}\text { Mortality } \\
(1 / 1000)\end{array}$ & $\begin{array}{l}\text { Mortality } \\
\text { risk ratio }\end{array}$ \\
\hline \multirow[t]{2}{*}{ Intravitreal Injection } & no & 86.60 & 4309 & $\begin{array}{l}49.76(48.28- \\
51.27)\end{array}$ & (reference) \\
\hline & yes & 18.31 & 949 & $\begin{array}{l}51.84(48.59- \\
55.25)\end{array}$ & $\begin{array}{l}1.04(0.97- \\
1.12)\end{array}$ \\
\hline \multirow[t]{2}{*}{ Sex } & male & 50.44 & 2503 & $\begin{array}{l}49.62(47.70- \\
51.60)\end{array}$ & (reference) \\
\hline & female & 54.46 & 2755 & $\begin{array}{l}50.59(48.72- \\
52.51)\end{array}$ & $\begin{array}{l}1.02(0.97- \\
1.08)\end{array}$ \\
\hline \multirow[t]{2}{*}{ Diabetes } & no & 53.56 & 2378 & $\begin{array}{l}44.40(42.63- \\
46.22)\end{array}$ & (reference) \\
\hline & yes & 51.34 & 2880 & $\begin{array}{l}56.10(54.07- \\
58.19)\end{array}$ & $\begin{array}{l}1.26(1.20- \\
1.33)\end{array}$ \\
\hline \multirow[t]{2}{*}{ Cancer } & no & 101.55 & 4980 & $\begin{array}{l}49.04(47.69- \\
50.42)\end{array}$ & (reference) \\
\hline & yes & 3.36 & 278 & $\begin{array}{l}82.86(73.41- \\
93.20)\end{array}$ & $\begin{array}{l}1.69(1.50- \\
1.91)\end{array}$ \\
\hline \multirow[t]{2}{*}{ Thyroid insufficiency } & no & 100.47 & 5030 & $\begin{array}{l}50.07(48.69- \\
51.47)\end{array}$ & (reference) \\
\hline & yes & 4.43 & 228 & $\begin{array}{l}51.43(44.97- \\
58.55)\end{array}$ & $\begin{array}{l}1.03(0.90- \\
1.17)\end{array}$ \\
\hline \multirow[t]{2}{*}{ Parkinson's disease } & no & 103.96 & 5136 & $\begin{array}{l}49.40(48.06- \\
50.77)\end{array}$ & (reference) \\
\hline & yes & 0.94 & 122 & $\begin{array}{l}129.46(107.50- \\
154.57)\end{array}$ & $\begin{array}{l}2.62(2.19- \\
3.14)\end{array}$ \\
\hline \multirow[t]{2}{*}{$\begin{array}{l}\text { Severe mental } \\
\text { disorders }\end{array}$} & no & 101.62 & 5020 & $\begin{array}{l}49.40(48.04- \\
50.78)\end{array}$ & (reference) \\
\hline & yes & 3.28 & 238 & $\begin{array}{l}72.58(63.65- \\
82.41)\end{array}$ & $\begin{array}{l}1.47(1.29- \\
1.67)\end{array}$ \\
\hline \multirow[t]{2}{*}{ Glaucoma } & no & 98.07 & 4764 & $\begin{array}{l}48.58(47.21 \text { - } \\
49.98)\end{array}$ & (reference) \\
\hline & yes & 6.83 & 494 & $\begin{array}{l}72.34(66.10- \\
79.01)\end{array}$ & $\begin{array}{l}1.49(1.36- \\
1.63)\end{array}$ \\
\hline \multirow[t]{2}{*}{$\begin{array}{l}\text { Chronic cardiac } \\
\text { insufficiency }\end{array}$} & no & 101.42 & 4820 & $\begin{array}{l}47.52(46.19- \\
48.88)\end{array}$ & (reference) \\
\hline & yes & 3.48 & 438 & $\begin{array}{l}125.89(114.37 \text { - } \\
138.25)\end{array}$ & $\begin{array}{l}2.65(2.40- \\
2.92)\end{array}$ \\
\hline \multirow[t]{2}{*}{$\begin{array}{l}\text { Chronic } \\
\text { hypertension }\end{array}$} & no & 68.14 & 3094 & $\begin{array}{l}45.41(43.82- \\
47.04)\end{array}$ & (reference) \\
\hline & yes & 36.76 & 2164 & $\begin{array}{l}58.86(56.41- \\
61.39)\end{array}$ & $\begin{array}{l}1.30(1.23- \\
1.37)\end{array}$ \\
\hline $\begin{array}{l}\text { Chronic coronary } \\
\text { heart disease }\end{array}$ & no & 89.22 & 3998 & $\begin{array}{l}44.81(43.43- \\
46.22)\end{array}$ & (reference) \\
\hline
\end{tabular}




\begin{tabular}{|c|c|c|c|c|c|}
\hline & yes & 15.68 & 1260 & $\begin{array}{l}80.36(75.98- \\
84.92)\end{array}$ & $\begin{array}{l}1.79(1.68- \\
1.91)\end{array}$ \\
\hline \multirow[t]{2}{*}{ Chronic arrhythmias } & no & 101.15 & 4896 & $\begin{array}{l}48.41(47.06- \\
49.78)\end{array}$ & (reference) \\
\hline & yes & 3.76 & 362 & $\begin{array}{l}96.37(86.70- \\
106.83)\end{array}$ & $\begin{array}{l}1.99(1.79- \\
2.22)\end{array}$ \\
\hline \multirow[t]{2}{*}{$\begin{array}{l}\text { Ulcerative colitis and } \\
\text { Crohn's disease }\end{array}$} & no & 104.11 & 5224 & $\begin{array}{l}50.18(48.83- \\
51.56)\end{array}$ & (reference) \\
\hline & yes & 0.80 & 34 & $\begin{array}{l}42.75(29.61- \\
59.74)\end{array}$ & $\begin{array}{l}0.85(0.61- \\
1.19)\end{array}$ \\
\hline \multirow[t]{2}{*}{ IHD ever before } & no & 84.90 & 3531 & $\begin{array}{l}41.59 \text { (40.23 - } \\
42.99)\end{array}$ & (reference) \\
\hline & yes & 20.00 & 1727 & $\begin{array}{l}86.33(82.31- \\
90.50)\end{array}$ & $\begin{array}{l}2.08(1.96- \\
2.20)\end{array}$ \\
\hline \multirow[t]{2}{*}{$\begin{array}{l}\text { IHD in half year } \\
\text { before }\end{array}$} & no & 102.21 & 4906 & $\begin{array}{l}48.00(46.67- \\
49.36)\end{array}$ & (reference) \\
\hline & yes & 2.70 & 352 & $\begin{array}{l}130.57(117.28- \\
144.95)\end{array}$ & $\begin{array}{l}2.72(2.44- \\
3.03)\end{array}$ \\
\hline \multirow[t]{2}{*}{ IHD in year before } & no & 100.17 & 4672 & $\begin{array}{l}46.64(45.31- \\
48.00)\end{array}$ & (reference) \\
\hline & yes & 4.73 & 586 & $\begin{array}{l}123.82(113.99- \\
134.26)\end{array}$ & $\begin{array}{l}2.65(2.44- \\
2.89)\end{array}$ \\
\hline \multirow[t]{2}{*}{ Stroke ever before } & no & 96.36 & 4380 & $\begin{array}{l}45.45(44.12- \\
46.82)\end{array}$ & (reference) \\
\hline & yes & 8.54 & 878 & $\begin{array}{l}102.80(96.11 \text { - } \\
109.83)\end{array}$ & $\begin{array}{l}2.26(2.10- \\
2.43)\end{array}$ \\
\hline \multirow[t]{2}{*}{$\begin{array}{l}\text { Stroke half year } \\
\text { before }\end{array}$} & no & 103.70 & 5105 & $\begin{array}{l}49.23(47.89- \\
50.60)\end{array}$ & (reference) \\
\hline & yes & 1.20 & 153 & $\begin{array}{l}127.43(108.04- \\
149.30)\end{array}$ & $\begin{array}{l}2.59(2.20- \\
3.04)\end{array}$ \\
\hline \multirow[t]{2}{*}{ Stroke year before } & no & 102.85 & 5008 & $\begin{array}{l}48.69 \text { (47.35 - } \\
50.06)\end{array}$ & (reference) \\
\hline & yes & 2.05 & 250 & $\begin{array}{l}122.06(107.40- \\
138.17)\end{array}$ & $\begin{array}{l}2.51(2.21- \\
2.85)\end{array}$ \\
\hline \multirow[t]{6}{*}{$\begin{array}{l}\text { Socio-economic } \\
\text { status }\end{array}$} & $\begin{array}{l}\text { Upper- } \\
\text { level } \\
\text { employees }\end{array}$ & 5.40 & 52 & $9.63(7.20-12.63)$ & (reference) \\
\hline & $\begin{array}{l}\text { Self- } \\
\text { employed }\end{array}$ & 4.95 & 81 & $\begin{array}{l}16.36(12.99- \\
20.34)\end{array}$ & $\begin{array}{l}1.70(1.20- \\
2.41)\end{array}$ \\
\hline & $\begin{array}{l}\text { Lower-level } \\
\text { employees }\end{array}$ & 8.57 & 99 & $\begin{array}{l}11.55(9.39- \\
14.07)\end{array}$ & $\begin{array}{l}1.20(0.86- \\
1.68)\end{array}$ \\
\hline & $\begin{array}{l}\text { Manual } \\
\text { workers }\end{array}$ & 10.82 & 200 & $\begin{array}{l}18.49(16.01- \\
21.23)\end{array}$ & $\begin{array}{l}1.92(1.41- \\
2.60)\end{array}$ \\
\hline & Students & 0.46 & 9 & $\begin{array}{l}19.41(8.88- \\
36.85)\end{array}$ & $\begin{array}{l}2.01(0.99- \\
4.09)\end{array}$ \\
\hline & Retirees & 67.74 & 4633 & $\begin{array}{l}68.40(66.44- \\
70.40)\end{array}$ & $\begin{array}{l}7.10(5.40- \\
9.33)\end{array}$ \\
\hline
\end{tabular}




\begin{tabular}{|l|l|l|l|l|l|}
\hline & Others & 6.97 & 184 & $\begin{array}{l}26.41(22.73- \\
30.51)\end{array}$ & $\begin{array}{l}2.74(2.01- \\
3.73)\end{array}$ \\
\hline
\end{tabular}


Table 3. All-cause and cardiovascular mortality. Matching set used as strata.

\begin{tabular}{|l|l|l|}
\hline & All-cause & Cardiovascular \\
& mortality & mortality \\
\hline Intravitreal anti-VEGF injection & $0.966(0.879-1.061)$ & $1.096(0.920-1.305)$ \\
\hline IHD ever before & $1.507(1.372-1.654)$ & $2.466(2.109-2.883)$ \\
\hline Diabetes & $1.335(1.254-1.421)$ & $1.483(1.326-1.659)$ \\
\hline Parkinson's disease & $2.149(1.699-2.718)$ & $1.471(0.945-2.287)$ \\
\hline Severe mental disorders & $1.958(1.659-2.312)$ & $2.235(1.667-2.997)$ \\
\hline Glaucoma & $1.024(0.916-1.145)$ & $1.011(0.828-1.233)$ \\
\hline Chronic cardiac insufficiency & $1.507(1.324-1.715)$ & $1.487(1.21-1.828)$ \\
\hline Chronic hypertension & $1.087(1.018-1.162)$ & $1.241(1.106-1.392)$ \\
\hline IHD ever before & $0.897(0.815-0.987)$ & $1.060(0.910-1.236)$ \\
\hline Chronic coronary heart disease & $1.323(1.155-1.515)$ & $1.427(1.138-1.789)$ \\
\hline Chronic arrhythmias & $1.120(0.762-1.647)$ & $0.537(0.226-1.275)$ \\
\hline Ulcerative colitis and Crohn's disease & & \\
\hline
\end{tabular}

ICD, International Classification of Disease; IHD, ischemic heart disease.

All studied parameters; yes versus no.

Hazard ratios (HR) with 95\% confidence intervals (Cls) were estimated from Cox's proportional hazards model. 